\title{
Effects and feasibility of hyperthermic baths in comparison to exercise as add-on treatment to usual care in depression: a randomised, controlled pilot study
}

\author{
Johannes Naumann ${ }^{1}$, Iris Kruza², Luisa Denkel², Gunver Kienle ${ }^{2}$ and Roman Huber ${ }^{2^{*}}$
}

\begin{abstract}
Background: Limitations of current therapy of depression highlight the need for an immediately available, easily implementable add-on treatment option with high acceptance from patients. Hyperthermic baths (HTB) are a form of balneotherapy with head-out-of-water-immersion in a hot pool or tub at $40^{\circ} \mathrm{C}$ for $15-20 \mathrm{~min}$. A prior study suggests that HTB added to usual depression care can have antidepressant effects.

Method: Single-site, open-label randomised controlled 8-week parallel-group pilot study at a university outpatient clinic. 45 medically stable outpatients with moderate depression as determined by the 17-item Hamilton Depression Rating Scale (HAM-D) score $\geq 18$ and a score $\geq 2$ on item 1 (Depressed Mood) were recruited. They were randomised to twice weekly HTB $(n=22)$ or a physical exercise program (PEP) of moderate intensity $(n=23)$. Primary outcome measure was the change in HAM-D total score from baseline (T0) to the 2-week time point (T1). Linear regression analyses, adjusted for baseline values, were performed to estimate intervention effects on an intention-to-treat (ITT) and per-protocol (PP) principle.

Results: Forty-five patients ( $\mathrm{HTB} n=22$; PEP $n=23$ ) were analyzed according to ITT (mean age $=48.4$ years, SD $=$ 11.3, mean HAM-D score = 21.7, SD =3.2). Baseline-adjusted mean difference after 2 weeks was 4.3 points in the HAM-D score in favor of HTB $(p<0.001)$. Compliance with the intervention and follow-up was far better in the HTB group (2 vs 13 dropouts). Per protocol analysis only showed superiority of HTB as a trend $(p=0.068)$. There were no treatment-related serious adverse events. Main limitation: the number of dropouts in the PEP group (13 of 23) was higher than in other trials investigating exercise in depression. Due to the high number of dropouts the effect in the ITT-analysis may be overestimated.

Conclusions: HTB added to usual care may be a fast-acting, safe and easy accessible method leading to clinically relevant improvement in depression severity after 2 weeks; it is also suitable for persons who have problems performing exercise training.

Trial registration: German Clinical Trials Register (DRKS) with the registration number DRKS00011013 (registration date 2016-09-19) before onset of the study.
\end{abstract}

\footnotetext{
* Correspondence: roman.huber@uniklinik-freiburg.de

${ }^{2}$ University of Freiburg, Faculty of Medicine, Freiburg, Germany

Full list of author information is available at the end of the article
}

(c) The Author(s). 2020 Open Access This article is licensed under a Creative Commons Attribution 4.0 International License, which permits use, sharing, adaptation, distribution and reproduction in any medium or format, as long as you give appropriate credit to the original author(s) and the source, provide a link to the Creative Commons licence, and indicate if changes were made. The images or other third party material in this article are included in the article's Creative Commons licence, unless indicated otherwise in a credit line to the material. If material is not included in the article's Creative Commons licence and your intended use is not permitted by statutory regulation or exceeds the permitted use, you will need to obtain permission directly from the copyright holder. To view a copy of this licence, visit http://creativecommons.org/licenses/by/4.0/ The Creative Commons Public Domain Dedication waiver (http://creativecommons.org/publicdomain/zero/1.0/) applies to the data made available in this article, unless otherwise stated in a credit line to the data. 


\section{Background}

Depression contributes to significant economic burden and is associated with comorbid diseases (i.e. cardiovascular disease), and impaired health-related quality of life and functioning [1-5]. Despite advances in the treatment of depression, one-third of depressed patients fail to respond to conventional antidepressant medication [6]. Moreover, current medications cause significant side effects in the central-nervous system and commonly used antidepressants have a delayed onset of action, further highlighting the need for faster acting, easy available and more effective treatments with fewer side effects [7-9].

\section{Hyperthermia - an ancient treatment for mental illness}

Fever, respectively hyperthermia, has been used as a medical treatment and part of balneotherapy since ancient times, and beneficial effects of fever on mental illness were already described in antiquity [10, 11]. Evidence suggests that hyperthermic baths (HTB) performed in a pool or tub with a water temperature of $40{ }^{\circ} \mathrm{C}$ and other forms of whole-body hyperthermia (WBH) have anti-depressant effects, mediated through changes in circadian rhythm, temperature physiology and sleep, which are disturbed in depressive patients [12-14]. After $15-20 \mathrm{~min}$ HTB a raise in core body temperature of $1.7^{\circ} \mathrm{C}$ can be expected $[15,16]$. Body core temperature in depressed patients is elevated during the night, while sleep quality is best when the core body temperature decreases; thus, change of body temperature might improve sleep quality. Findings from experimental studies show that manipulation of core and skin temperatures can improve or disrupt sleep, and it is well-known that sleep disruption negatively influences quality of life, enhances length and severity of episodes and contributes to relapse in depression [13, 17, 18]. Strengthening sleep promoting brain activity improves depression (e.g. by sleep deprivation and antidepressant medication) $[19,20]$. In addition, a novel hypothesis describes that an evolutionarily ancient thermoafferent pathway, signaling from serotonergic sensory cells in the skin (Merkel cells) to serotonergic neurons and depression-related circuits in the brain, might explain the antidepressant effects of HTB [7].

\section{HTB - evidence}

There is growing scientific evidence that HTB and WBH might be efficacious for treatment of depressive disorders [15, 21-23]. The results of a non-controlled HTB study with 20 depressive patients showed an improvement in the 21-item Hamilton Depression Rating Scale [24] after five baths [21]. HTB (especially before bedtime) improved sleep in healthy subjects [25-28], insomniac people $[29,30]$ and elderly patients with vascular dementia [31]. In a further non-controlled study using a radiant system to induce $\mathrm{WBH}$, a single session showed a significant reduction in the Centers for Epidemiologic Studies Depression Scale [32] in 16 depressive patients [23]. In a randomised, sham-controlled study from the same group this favorable result of a single WBH session could be corroborated [22]. Our results of a randomised placebo-controlled pilot study using HTB compared with a sham light treatment as Placebo were also promising; after four interventions (2 weeks), the intentionto-treat analysis showed a significant $(p=0.037)$ difference in the 17-item Hamilton Depression Rating Scale (HAM-D) total score of 3.14 points in favor of the HTB group [15]. Regarding the superiority of HTB to a Placebo we now decided to compare HTB with physical exercise as an active control.

\section{Physical exercise in depression}

Several meta-analyses [33-35], including three Cochrane reviews [36-38], have supported the antidepressant effects of exercise. Various psychobiological mechanisms are understood to play a role [34]. Both, aerobic exercise (e.g. running, cycling) and anaerobic exercise (e.g. strength-training) are effective in the treatment of depression. According to national and international guidelines for depression [39-41] physical activity is recommended as add-on therapy to pharmacotherapy.

After we found HTB to be superior to a Placebo (sham light therapy, [15]), our primary objective was to compare the efficacy of HTB with a proven non-pharmacological standard intervention - a physical exercise program (PEP). Secondary objectives were to evaluate safety (incidence of treatment discontinuation and adverse events (AE)) and feasibility of HTB applied in a home-setting.

\section{Methods \\ Study design}

Eight-week single-site, parallel-group, open-label randomised controlled pilot trial of HTB vs PEP for patients with a diagnosis of depression according to ICD-10 (F32/F33) of at least 4 weeks duration. Patients were recruited from the Medical Center - University of Freiburg. The study was registered in the German Clinical Trials Register (DRKS) with the registration number DRKS00011013 (https://www.drks.de/drks_web/; registration date 2016-09-19) before onset of the study. The study was conducted in accordance with the Declaration of Helsinki and local laws and regulations. All the participants filled in a written informed consent form before entering the study.

\section{Eligibility criteria}

Eligible participants were to meet the following criteria: (1) Medically stable outpatients with a diagnosis of 
depressive disorder (ICD-10: F32/F33; criteria for single or recurrent depression without psychotic features) confirmed by a physician or psychotherapist; (2) men and women between 18 and 65 years of age; (3) a moderate level of depressive symptoms assessed with the 17-item Hamilton Depression Rating Scale (HAM-D) total score $\geq 18$ and a score $\geq 2$ on item 1 (Depressed Mood) at screening and at baseline; (4) on a consistent antidepressant regimen or off antidepressant therapy for at least 4 weeks prior to baseline; (5) no changes in antidepressant treatment to be expected during the study.

Exclusion criteria included the presence of severe concomitant disease (i.e. heart failure New York Heart Association (NYHA) III-IV, cancer, tuberculosis, liver cirrhosis), contraindication for hot baths (i.e. open wounds, heat urticaria, varicosis, multiple sclerosis, epilepsy, orthostatic dysregulation), organic psychotic disorders, schizophrenia, hallucinations, bipolar disorders, dissociative personality disorder, suicidal thoughts, abuse of alcohol or other drugs within the last 6 months, use of $\beta$-blockers or corticosteroids, pregnancy, lactation, and participation in clinical trials in the 8 weeks preceding the study. We excluded patients over age 65 because HTB causes circulatory stress and the risk of cardiovascular disease increases with age $[41,42]$ and because symptoms of depression may be expressed differently in late-life depression [43].

\section{Interventions}

Patients were randomly assigned to receive either HTB or PEP for 8 weeks with two interventions per week (Table 1). Patients were told that two promising treatments were being compared in the study. The attention and time spent with the patients was similar in both groups.

\section{Hyperthermic baths (HTB)}

HTB were applied as head-out-of-water-immersion in a $40^{\circ} \mathrm{C}$ pool at a thermal bath near Freiburg, Germany. All the baths were taken in the afternoon (14:00-18:00). Five patients could sit in the pool at a time. The baths were taken until the patients noticed discomfort, the target being $20 \mathrm{~min}$ [16]. Directly after the bath, the patients were accompanied to a nearby resting room, where they lay down and wrapped in warm blankets with two conventional 0.71 hot water bottles (abdomen, thighs) filled with hot water $\left(\mathrm{ca} .70^{\circ} \mathrm{C}\right)$ for at least another $20 \mathrm{~min}$ to keep the body temperature elevated. After $20 \mathrm{~min}$ in a pool with a water temperature of $40^{\circ} \mathrm{C}$, a raise in core body temperature of $1.7^{\circ} \mathrm{C}$ is to be expected [16]. After four sessions under supervision (IK, LD), the remaining 12 sessions were performed by the patients themselves at the thermal bath or in the homesetting. At home, the baths were performed in the same way (water temperature $40^{\circ} \mathrm{C}$, duration $20 \mathrm{~min}$ ). The supervisors documented the exact duration of the bath and the body temperature. In case that a patient felt uncomfortable the bath was terminated. After each bath patients were asked if there were any AE. All AE reported spontaneously by patients or observed by the supervisors were recorded in prepared data sheets. After the fourth application the patients were instructed in written and oral form to perform the following baths in the thermal bath or at home on their own as before and

Table 1 Trial design

\begin{tabular}{|c|c|c|c|c|c|c|}
\hline & Screening & $\begin{array}{l}\text { Baseline/Randomisation } \\
\text { (T0) }\end{array}$ & $\begin{array}{l}\text { After } 4 \text { interventions } \\
\text { (T1) }\end{array}$ & & & $\begin{array}{l}\text { After } 16 \text { interventions } \\
\text { (T2) }\end{array}$ \\
\hline & & $0 \mathrm{wk}$ & $2 \mathrm{wk}$ & $\begin{array}{l}4 \\
\text { wk }\end{array}$ & $\begin{array}{l}6 \\
\text { wk }\end{array}$ & 8 wk \\
\hline HTB/PEP target $(n)^{a}$ & & & 4 & 8 & 12 & 16 \\
\hline HAM-D ${ }^{b}$ & $x$ & $x$ & $x$ & & & $x$ \\
\hline Medical history & & $x$ & & & & \\
\hline $\mathrm{BDI}-\|^{\mathrm{c}}$ & & $x$ & $x$ & & & $x$ \\
\hline $\mathrm{PSQ}^{\mathrm{d}}$ & & $x$ & $x$ & & & $x$ \\
\hline Global judgement of efficacy & & & $x$ & & & $x$ \\
\hline $\begin{array}{l}\text { Global judgement of } \\
\text { tolerability }\end{array}$ & & & $x$ & & & $x$ \\
\hline Change of medication/therapy & & & $x$ & & & $x$ \\
\hline Adverse events ${ }^{\mathrm{e}}$ & & & $x$ & $x$ & $x$ & $x$ \\
\hline Telephone contact & & & & $x$ & $x$ & \\
\hline
\end{tabular}

a HTB: hyperthermic baths, PEP: physical exercise program

${ }^{b}$ HAM-D: 17-item Hamilton Depression Rating Scale

' BDI-II: Beck Depression Inventar II

d PSQI: The Pittsburgh Sleep Quality Index

${ }^{\mathrm{e}}$ Adverse events were documented before and after each treatment 
to document temperature, duration and $\mathrm{AE}$ in a prepared diary (S1 File).

\section{Physical exercise program (PEP)}

Patients in the PEP group took part in a structured program of moderate intensity which mainly followed the recommendation in international guidelines [39, 40]. It consisted of warming-up, walking, jogging, stretching and strengthening elements for about $45-50 \mathrm{~min}$, conducted outside in small groups of five patients each. The first four sessions took place under supervision (IK, LD; trained in exercise therapy). The following 12 sessions were performed by the patients themselves in groups or alone. They received a detailed explanation and written instructions (S2 File) and were asked to carry out the guided programme as they learned it in the supervised sessions. Training duration and the exercise components completed were documented in prepared diaries. Patients of both groups received a telephone call from the study personal 4 and 6 weeks after randomisation to document and reinforce compliance.

\section{Outcomes}

The primary outcome was observer-rated and interviewbased severity of depression assessed by the 17-item HAM-D at 2 weeks (T1), determined by the change in HAM-D total score at T1 relative to T0 (baseline). The HAM-D has a score range of 0 (least depressed) to 52 (most depressed), with good reliability and validity [44].

Further prespecified clinical secondary outcomes were: Patients' subjective perception of depression severity as measured by the self-report Beck Depression Inventory II (BDI-II) [45, 46]. The BDI-II consists of 21 items, each rated $0-3$ according to severity of difficulties experienced, with a possible range of 0-63 (minimal 0-13, mild $14-19$, moderate $20-28$, or severe $\geq 29$ ). Sleep quality was assessed with the Pittsburgh Sleep Quality Index (PSQI) [47-49]. The PSQI is a self-rating questionnaire resulting in a global score between 0 and 21, with higher scores indicating poorer sleep quality. A global score $>5$ is an indicator of relevant sleep disturbances. All mentioned questionnaires were used in the validated German version [50].

Unblinded assessments (IK, LD received prior training and were supervised by $\mathrm{RH}$ ) were performed at the following three time points (Table 1): before start of HTB treatment (T0), immediately on completion of the twoweek treatment interval (T1), according to results that effects are supposed to appear early [12] and at the end of treatment (T2).

\section{Core body temperature}

Core body temperature was measured with an infrared-earthermometer (Thermoscan ${ }^{\circ}$, Type: 6021, Braun GmbH). In the HTB group, the core body temperature was measured directly before and after the bath and after resting; in the PEP group directly before and after the exercise sessions.

\section{Global judgment of efficacy and tolerability}

After four treatments (T1) and after end of treatment (T2), patients were asked to rate the efficacy and tolerability of the intervention on a 5 -point scale $(1=$ very good; 2 = good; 3 = moderate; 4 = absent; 5 = worsening).

\section{Safety and feasibility outcomes}

To estimate the safety of HTB, the incidence of treatment discontinuation and the occurrence of $\mathrm{AE}$ were evaluated. To answer the feasibility question, information regarding compliance and experiences of the patients were evaluated. In order to improve adherence to intervention procedures contact was made by phone after four and 6 weeks, respectively.

\section{Adverse events}

All AE reported spontaneously by patients or observed by the assistants were recorded before and after each treatment. If a serious adverse event (SAE) occurred, the principal investigator took all the necessary and appropriate measures to ensure the safety of the patient.

\section{Sample size estimation}

No data on effect size of HTB in comparison to PEP were available; however, from the results of our previous study [15], we expected a moderate to large effect size for HTB relative to control [33]. A between-group effect size of $d=0.91$ and $1-\beta=0.80$ power was chosen for this pilot study which required 40 patients $(n=20$ per arm) to reach significance with $\alpha=0.05$. This estimation was based on the primary outcome of depression symptoms as measured by the HAM-D total score at 2 weeks of intervention [51]. However, this sample size does not account for subgroup analyses.

\section{Randomisation and blinding}

All eligible patients who consented to participate were allocated to HTB or PEP after baseline assessment in a 1:1 ratio by simple randomisation without blocking or stratification. Randomisation codes were computergenerated by an independent biometric center. Allocation was performed with opaque sealed envelopes that were randomly chosen by the participants. Enrolment (RH) was done directly after informed consent was obtained from the patients. Both therapies could not be blinded. Outcome assessment (IK, LD) was unblinded. Data management and analyses were performed blinded to treatment allocation. 


\section{Statistical analyses}

Treatment comparison of the primary endpoint (HAM$\mathrm{D}$ change from baseline to T1) was performed within a generalized linear regression model adjusted for baseline values. BDI-II and PSQI were analyzed in the same way. Analyses were done on the intention-to-treat (ITT) population, defined as all allocated patients, applying the last-observation-carried-forward (LOCF) approach to impute missing data. Baseline characteristics were compared using 2-sided $t$ tests for continuous data and $x^{2}$ statistics. The per-protocol (PP) population was defined as all patients who had a complete dataset for the primary outcome and had participated in at least $75 \%$ of the treatments, meaning at least 3 of 4 treatments for $\mathrm{T} 1$, and at least 12 of 16 treatments for $\mathrm{T} 2$. We report $p$-values with the significance level set at $p<0.05$. The study followed a protocol (S1-S3 Protocol) and reporting followed the CONSORT (Consolidated Standards of Reporting Trials; Statement extension for nonpharmacological treatments; S4 Protocol). Prespecified secondary analyses were not adjusted for multiple comparisons and should therefore be regarded as descriptive and exploratory. Statistical analyses were performed using IBM $^{\bullet}$ $\mathrm{SPSS}^{\oplus}$, Version 24, for Windows.

\section{Data collection and monitoring}

A data manager (CS), blind to treatment allocation, reviewed and evaluated data, in order to detect errors during data collection, and conducted a quality review of the database, with double data entry by two independent persons for $20 \%$ of the values.

\section{Results}

\section{Enrolment and sample description}

The HTB study began recruiting patients in September 2016 and closed recruitment in January 2017. Sixty-nine adults agreed to participate and were assessed for eligibility. Of that number, 45 underwent randomisation (Fig. 1).

Randomisation was balanced with respect to demographic and clinical characteristics with more females $(p=0.047)$, a higher BMI $(p=0.135)$ and longer duration of depressive disorder in the PEP-group ( $p=$ 0.035 ), (Table 2). The mean depression severity score based on the HAM-D was 21 (HTB), respectively 22 (PEP), consistent with moderate severity depression [44]. Self-reported severity and symptoms of depression assessed by the BDI-II was 29 (HTB), respectively 31 (PEP), consistent with the lowest possible score for severe depression. Most patients had depression for several years; the shortest duration of depression was 2 months, the longest more than 20 years. Sleep quality, as measured by the PSQI total score (ranging from 0 to 21; score $\leq 5$ associated with good sleep quality; score $>5$ associated with poor sleep quality), was poor with a total score of 10 (HTB), respectively 11 (PEP). Prescription rates of antidepressants were high at baseline (HTB, $68 \%$; PEP, 48\%), as well as for psychotherapy (HTB, 71\%; PEP, 83\%).

Primary outcome data (HAM-D total score after 2 weeks) were available for 32 patients, representing a loss to follow-up of $29 \%$ (5\% in the HTB group and 52\% in the PEP group). Eight patients (HTB $n=1$; PEP $n=7$ ) discontinued treatment without receiving their allocated intervention. A further five patients (PEP group) withdrew from trial before T1; another two after T1 (HTB $\mathrm{n}=1$; PEP $\mathrm{n}=1$ ).

\section{Treatment effect on core body temperature}

Core body temperature rose from $36.7^{\circ} \mathrm{C}$ before the bath to $38.6{ }^{\circ} \mathrm{C}$ directly after the bath (mean change $1.96{ }^{\circ} \mathrm{C}$, standard deviation [SD] 0.5), and maintained at $37.4{ }^{\circ} \mathrm{C}$ (mean change $0.7^{\circ} \mathrm{C}, \mathrm{SD}=0.5$ ) after rest. The mean temperature of the bath was $40.2^{\circ} \mathrm{C}(\mathrm{SD}=0.3)$. Mean duration of baths was $20.26 \mathrm{~min}(\mathrm{SD}=1.74)$ and resting time amounted to $21.7 \mathrm{~min}(\mathrm{SD}=2.87)$. In the PEP group, there was no difference in core body temperature before or after physical exercise $\left(36.48^{\circ} \mathrm{C}\right.$, $\mathrm{SD}=0.46$, respectively $\left.36.50^{\circ} \mathrm{C}, \mathrm{SD}=0.52\right)$. Mean duration of exercises was $56.44 \mathrm{~min}(\mathrm{SD}=17.55)$.

\section{Primary outcome}

The ITT analysis showed an adjusted mean difference between the groups of 4.3 points (95\% CI 2.16 to 6.42; $B=0.438)$ in the HAM-D score after 2 weeks in favor of HTB $(p<0.001$, Table 3$)$ using LOCF for missing data. The PP analyses showed an adjusted mean difference between the groups of 2.7 points ( $95 \% \mathrm{CI}-0.22$ to 5.69 ) in the HAM-D score after 2 weeks in favor of HTB ( $p=$ 0.07, Table 4). Further analysis using different methods (linear regression) for substituting missing data also showed a non-significant difference in favor of the HTB group.

\section{Descriptive secondary analyses}

Analysis of secondary outcomes was exploratory and no adjustments for multiple testing were applied. Looking at the mean differences compared to baseline, the HAM-D results show a stable improvement in the HTB group of 5.4 points after 2 weeks and of 5.9 points after 8 weeks in the ITT-analysis and an improvement in the HTB group of 6.1 points after 2 weeks and of 6.9 points after 8 weeks in the PP-analysis, whereas in the PEP group we see an improvement of 1.4 points after 2 weeks and of 3.2 points after 8 weeks in the ITT-analysis (Fig. 2a) and an improvement of 3.5 points after 2 weeks and of 8.5 points after 8 weeks in the PP-analysis. 


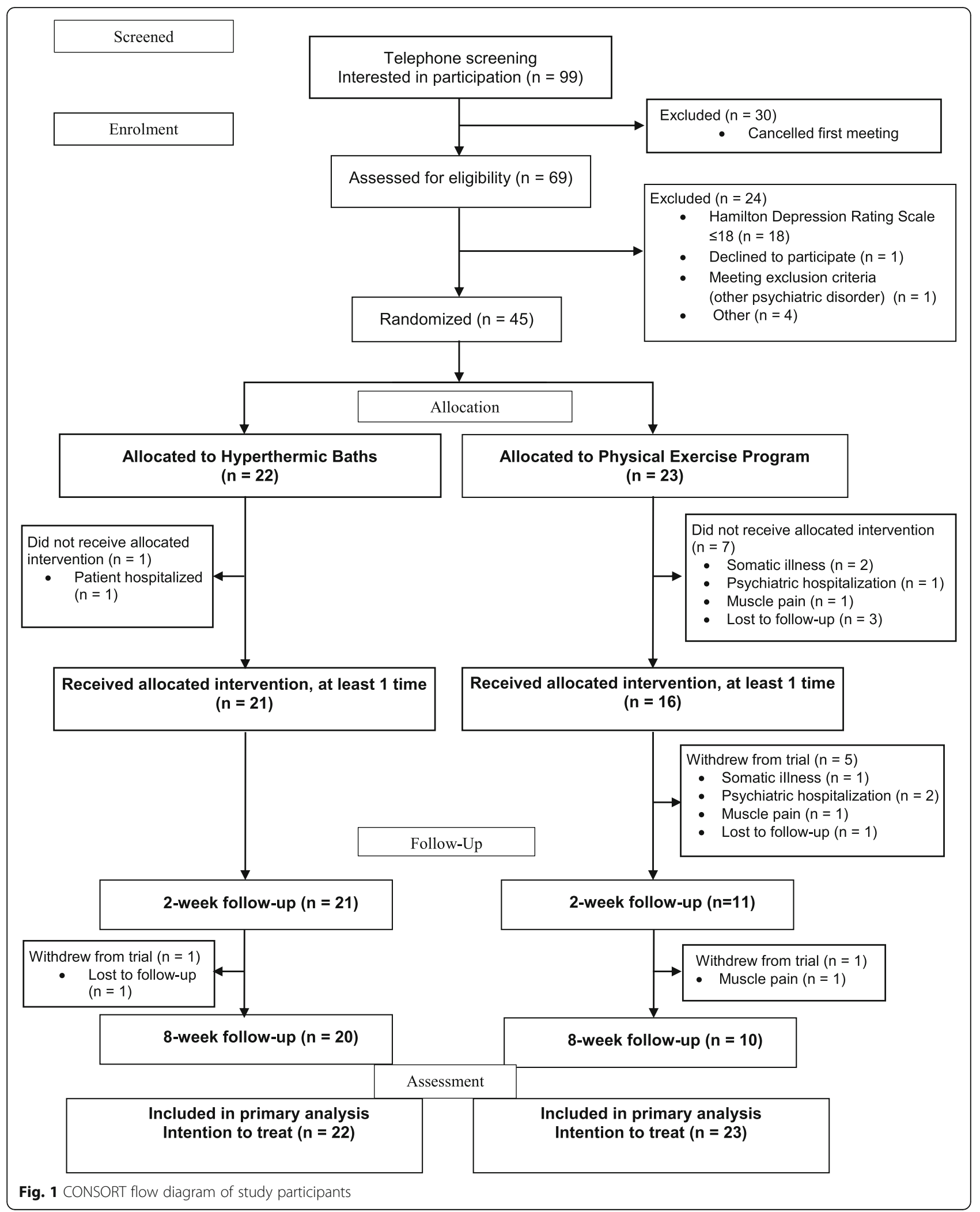


Table 2 Demographic and clinical characteristics at baseline

\begin{tabular}{|c|c|c|c|c|}
\hline & $\begin{array}{l}\text { Overall } \\
(N=45)\end{array}$ & $\begin{array}{l}\text { Hyperthermic Baths } \\
(N=22)\end{array}$ & $\begin{array}{l}\text { Physical Exercise Program } \\
(N=23)\end{array}$ & $\mathrm{p}$ \\
\hline Gender: Female, $n(\%)$ & $33(73.33 \%)$ & $13(59.09 \%)$ & $20(86.96 \%)$ & $0.047^{c}$ \\
\hline Age (years) & $48.4(11.3)$ & $45.6(12.3)$ & $51.0(9.8)$ & 0.106 \\
\hline BMI $\left(\mathrm{kg} / \mathrm{m}^{2}\right)$ & $25(5)$ & $24(4.2)^{b}$ & $26(5.6)^{\S}$ & 0.135 \\
\hline Median (IQR) & $24.5(7)$ & $23.5(5)$ & $26(11)$ & \\
\hline Duration of depression, years & $6(7)$ & $4(6)$ & $8(7.5)$ & 0.035 \\
\hline $\begin{array}{l}\text { Psychiatric hospital stays ( } n \text { ) } \\
\text { (last } 2 \text { years) }\end{array}$ & $21(47.72 \%)$ & $11(52.38 \%)^{\mathrm{a}}$ & $10(43.47 \%)$ & 0.763 \\
\hline Use of psychopharmaca, $n$ (\%) & $26(57.77 \%)$ & $15(68.18 \%)$ & $11(47.82 \%)$ & 0.231 \\
\hline Psychotherapy & $34(77.27 \%)$ & $15(71.42 \%)^{a}$ & 19 (82.61\%) & 0.481 \\
\hline Sport, $n(\%)$ & $32(74.42 \%)$ & $15(75.0 \%)^{b}$ & 17 (73.91\%) & $1.0^{c}$ \\
\hline Baths, $n$ (\%) & $14(32.56 \%)$ & $7(35.0 \%)^{b}$ & 7 (30.43\%) & 1.0 \\
\hline HAM-D total score & $21.7(3.2)$ & $21.2(3.3)$ & $22.2(3.1)$ & 0.322 \\
\hline Median (IQR) & $21(5)$ & $21(18-29)$ & $22(18-29)$ & \\
\hline BDI-II & $30.0(7.1)$ & $29.0(5.8)$ & $31.1(8.1)$ & 0.318 \\
\hline Median (IQR) & $31(8)$ & $30.5(19-38)$ & $31(13-50)$ & \\
\hline Median (IQR) & $\begin{array}{l}10.8(3.7) \\
10(6)\end{array}$ & $\begin{array}{l}10.2(3.8) \\
10(4-16)\end{array}$ & $\begin{array}{l}11.4(3.7) \\
11(5-18)\end{array}$ & 0.300 \\
\hline
\end{tabular}

Where not otherwise indicated, data are shown as mean and standard deviation (SD).

$I Q R$ interquartile range

BMI Body Mass Index, HAM-D 17-item Hamilton Depression Rating Scale, BDI-II Beck Depression Inventar II, PSQI The Pittsburgh Sleep Quality Index ${ }^{\mathrm{a}}$ missing $n=1 ;{ }^{\mathrm{b}}$ missing $n=2$;

'chi-quadrat-test, Fisher's exact test

For the following results only the ITT-analysis is reported. A similar pattern can be seen in the results of the BDI-II, with a mean difference compared to baseline in the HTB group of 8.7 points after 2 weeks and of 8.5 points after 8 weeks.
The PEP group showed an improvement of 2.0 points after 2 weeks and of 6.3 points after 8 weeks (Fig. 2b). Results of the PSQI show a mean difference compared to baseline of 1.5 points after 2 weeks and of 1.9 points after 8 weeks in the HTB group, and a deterioration of

Table 3 Between-group differences in the intent-to-treat last observation carried forward sample

\begin{tabular}{|c|c|c|c|c|}
\hline Outcome Measure & $\begin{array}{l}\text { HTB } \\
\text { Group } \\
(N=22)\end{array}$ & $\begin{array}{l}\text { PEP } \\
\text { Group } \\
(N=23)\end{array}$ & $\begin{array}{l}\text { HTB vs PEP } \\
\text { Adjusted mean difference }{ }^{c} \\
(95 \% \mathrm{Cl})\end{array}$ & $p^{c}$ \\
\hline \multicolumn{5}{|l|}{ HAM-D total score } \\
\hline Baseline & $21.2(3.3)$ & $22.2(3.1)$ & & \\
\hline T1: 2 weeks $^{a}$ & $15.8(4.4)$ & $20.8(4.2)$ & 4.3 (2.16 to 6.42 ) & $<0.001$ \\
\hline T2: 8 weeks ${ }^{\mathrm{b}}$ & $15.3(5.8)$ & $19.0(6.1)$ & $2.9(-0.40$ to 6.14$)$ & 0.084 \\
\hline \multicolumn{5}{|l|}{ BDI-II } \\
\hline Baseline & $29.0(5.8)$ & $31.1(8.1)$ & & \\
\hline T1: 2 weeks ${ }^{b}$ & $20.3(8)$ & $29.1(8.8)$ & 7.5 (2.99 to 11.93$)$ & 0.002 \\
\hline T2: 8 weeks ${ }^{\mathrm{b}}$ & $20.5(10.8)$ & $24.8(11.8)$ & 3.1 ( -3.36 to 9.53$)$ & 0.340 \\
\hline \multicolumn{5}{|l|}{ PSQI } \\
\hline Baseline & $10.2(3.8)$ & $11.4(3.7)$ & & \\
\hline T1: 2 weeks ${ }^{b}$ & $8.7(3.7)$ & $11.5(4.1)$ & 2.0 (0.14 to 3.92 ) & 0.036 \\
\hline T2: 8 weeks ${ }^{\mathrm{b}}$ & $8.3(3.2)$ & $10.7(4.1)$ & $1.8(-0.13$ to 3.64$)$ & 0.067 \\
\hline
\end{tabular}

Abbreviations: HAM-D 17-Item Hamilton Depression Rating Scale, BDI-Il Becks Depression Inventar II, PSQI The Pittsburgh Sleep Quality Index Data are shown as mean and standard deviation (SD).

${ }^{\text {a }}$ Primary outcome

bPrespecified secondary outcome

'Linear regression analyses adjusted for baseline scores 
Table 4 Between-group differences in the per-protocol completer sample

\begin{tabular}{|c|c|c|c|c|}
\hline Outcome Measure & HTB Group & PEP Group & $\begin{array}{l}\text { HTB vs PEP } \\
\text { Adjusted mean difference } \\
(95 \% \mathrm{Cl})\end{array}$ & $p^{c}$ \\
\hline \multicolumn{5}{|l|}{ HAM-D total score } \\
\hline Baseline & $21.0(3.2)$ & $21.4(3.0)$ & & \\
\hline $\mathrm{T} 1: 2$ weeks $^{\mathrm{a}}$ & $14.9(3.6)$ & $17.9(4.2)$ & $2.7(-0.22$ to 5.69$)$ & 0.07 \\
\hline T2: 8 weeks $^{\mathrm{b}}$ & $14.1(5.2)$ & $12.9(5.1)$ & -0.9 ( -5.66 to 3.97$)$ & 0.72 \\
\hline \multicolumn{5}{|l|}{ BDI-II } \\
\hline Baseline & $28.5(6.1)$ & $32.0(4.1)$ & & \\
\hline $\mathrm{T} 1: 2$ weeks $^{\mathrm{a}}$ & $19.2(7.8)$ & $24.2(6.9)$ & $3.0(-3.09$ to 9.08$)$ & 0.32 \\
\hline T2: 8 weeks $^{\mathrm{b}}$ & $18.0(10.7)$ & $13.0(6.5)$ & $-7.7(-16.19$ to 0.76$)$ & 0.07 \\
\hline \multicolumn{5}{|l|}{ PSQI } \\
\hline Baseline & $9.9(3.9)$ & $10.6(3.0)$ & & \\
\hline T1: 2 weeks $^{a}$ & $8.3(3.8)$ & $9.6(3.9)$ & $0.9(-1.83$ to 3.57$)$ & 0.51 \\
\hline T2: 8 weeks ${ }^{\mathrm{b}}$ & $8.1(3.6)$ & $8.0(3.9)$ & $-1.2(-3.74$ to 1.39$)$ & 0.35 \\
\hline
\end{tabular}

0.1 points after 2 weeks and an improvement of 0.7 points after 8 weeks in the PEP group (Fig. 2c). Subgroup-analyses according to baseline depression severity in HAM-D score quartiles (median) revealed the greatest treatment effect in quartiles 3 and 4 (Table 5). There was no correlation between body temperature and outcome (data not shown).

\section{Global judgment of efficacy and tolerability}

The global judgment by the patients showed no significant differences between the groups (Table 6), with good to moderate efficacy and tolerability after four interventions and at the end of treatment after 16 interventions.

\section{Adverse events}

AE possibly related to the therapy were reported by 25 patients, of which $18 / 21$ were assigned to the HTB group and $7 / 11$ to the PEP group (Table 7 ). No SAE were reported by either group. There was no significant difference between the groups $\left(p_{2 \text {-tailed }}=0.197\right)$. Typical $\mathrm{AE}$ in the HTB group were discomfort during the baths such as dizziness, fatigue, palpitations and thus mainly attributable to the cardiovascular system and indicating that the HTB were applied at a therapeutic limit. Additionally, patients reported transient effects as minor headache, itching, sweating, tightness, hunger worsening of depression and irritability. Typical AE in the exercise group were muscle soreness, pain in joints, the lower back or tendons; one patient reported cough and dizziness caused by breathing in cold air during exercise.

\section{Dropouts and compliance}

AE that were not related to the treatment but which led to dropout included one patient in the HTB group who was hospitalized before the start of the treatment and six in the PEP group, three of which withdrew because of physical illness and three because of psychiatric hospitalization; three of these before the start of the treatment and the other three during the first 2 weeks of treatment.

Treatment related $\mathrm{AE}$ resulted in three dropouts in the PEP group (muscle pain); there were no treatmentrelated dropouts in the HTB group. Compliance of the PP population was good with a medium number of treatments of 13.3 (95\% CI 11.6 to 14.9 ) in the HTB group and of 12.6 (95\% CI 9.1 to 16.1 ) in the PEP group.

\section{Feasibility of HTB in a home-setting}

After four sessions under supervision, the remaining 12 sessions were performed without supervision, either in a home-setting or at the thermal bath as before. The results show that HTB can be performed without supervision. However, only seven patients attempted to take the baths at home, and their main complaint was that it was difficult to reach the target water temperature of $40{ }^{\circ} \mathrm{C}$; thus, they returned to the thermal bath.

\section{Discussion}

To our knowledge, this is the first randomised controlled parallel group study to assess the efficacy of HTB compared with PEP in adults with depressive disorder. The main finding from this preliminary study is that HTB reduced the HAM-D score compared with PEP, 


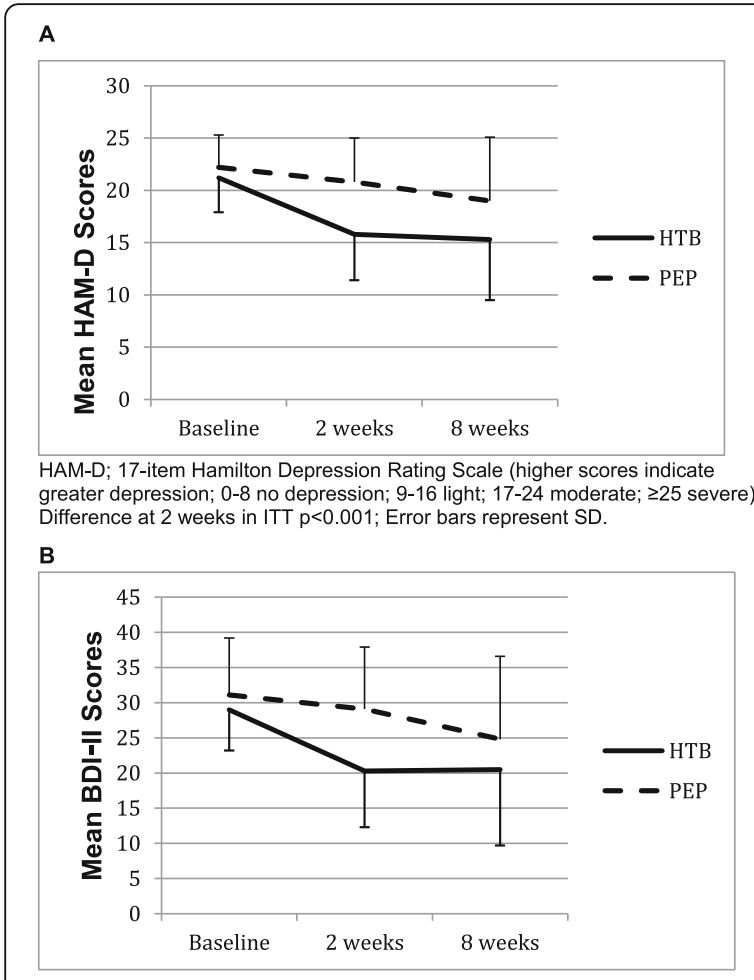

BDI-II; Becks Depression Inventar II (higher scores indicate greater depression 0-12 no depression; $13-19$ light; $20-28$ moderate; $\geq 29$ severe). Difference at 2 weeks in ITT $p=0.002$; Error bars represent SD.

C

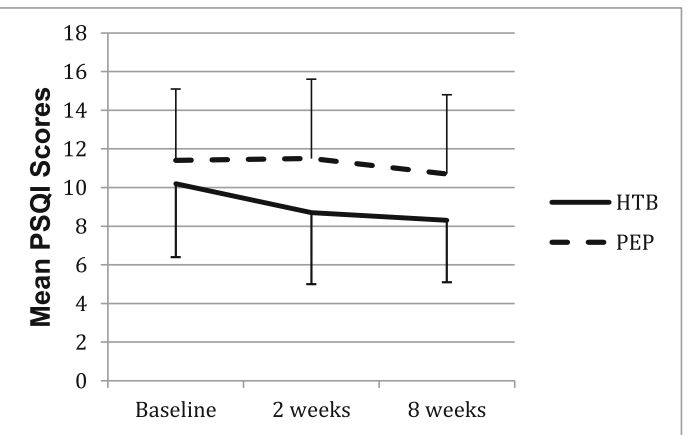

PSQI; The Pittsburgh Sleep Quality Index (higher scores indicate bad sleep, cutoff score of $5,<5$ good sleep, $\geq 5$ bad sleep)

Difference at 2 weeks in ITT $p=0.036$; Error bars represent SD.

Fig. 2 Modeled change scores by week. a HAM-D; 17-item Hamilton Depression Rating Scale (higher scores indicate greater depression; 0-8 no depression; 9-16 light; 17-24 moderate; $\geq 25$ severe). Difference at 2 weeks in ITT $p<0.001$; Error bars represent SD. b BDIII; Becks Depression Inventar II (higher scores indicate greater depression; 0-12 no depression; 13-19 light; 20-28 moderate; $\geq 29$ severe). Difference at 2 weeks in ITT $p=0.002$; Error bars represent SD. c PSQI; The Pittsburgh Sleep Quality Index (higher scores indicate bad sleep, cutoff score of $5,<5$ good sleep, $\geq 5$ bad sleep). Difference at 2 weeks in ITT $p=0.036$; Error bars represent SD

but the effect was not significant in the PP-analysis. It should be emphasized that the onset of treatment response occurred within the first 2 weeks. Commonly used antidepressants, the standard treatment for depression, have a delayed onset of action. It requires weeks of
Table 5 Subgroup-analyses according to HAM-D score quartiles

\begin{tabular}{lllll}
\hline & HTB & \multicolumn{3}{l}{ PEP } \\
& Mean (SD) & $\mathbf{n}$ & Mean (SD) & $\mathbf{n}$ \\
\hline HAM-D $\geq \mathbf{2 1}$ & $-7.9(3.7)$ & 10 & $-3.4(2.1)$ & 5 \\
HAM-D $\geq \mathbf{2 4}$ & $-11.5(2.7)$ & 4 & $-3.0(0.0)$ & 2
\end{tabular}

treatment before the core symptoms of depression are ameliorated [9]. In SSRIs (selective serotonin reuptake inhibitors), i.e. fluoxetine, this discrepancy between antidepressant-induced acute neurochemical effects and clinical effectiveness adds up to 4 weeks in $75 \%$ of responders [8]. Consequently, HTB could offer a concomitant treatment option to close this gap. Exercise as a treatment for depression took 6 to 8 weeks to show an effect but this effect may be overlapped by the natural course of depression (Fig. 2). The between-group difference after 2 weeks, adjusted for baseline values, was 4.3 HAM-D points $(p<0.001$ PP-analysis 2.7 points $p=$ 0.07 ), which is a clinically relevant difference especially in comparison to an active non pharmacological therapy. As established by the National Institute for Clinical Excellence (NICE) the threshold for clinical relevance is a difference of 3 points on the HAM-D [39]. HAM-D total score was also lower at 8 weeks in the HTB group, but high attrition rates reduce confidence in this result. As in pharmacological studies, the magnitude of the difference in HAM-D scores between the HTB and the PEP group increased with increasing baseline depression severity. The PP analysis showed a trend towards better results in the PEP group at 8 weeks. This however, may be due to a selection bias as 13 patients dropped out in the PEP group. It also might be that hyperthermia has a rapid effect that is not further maximized by longer treatments.

The results of the HAM-D at 2 weeks are supported by the outcomes of the BDI-II, which also showed an improvement with an adjusted mean difference of 7.5 points ( $p=0.002$; PP-analysis 3.0 points $p=0.32)$ in favor of the HTB group, representing a decrease of $30 \%$ between the groups in favor of the HTB group after 2 weeks. However, after 8 weeks the HAM-D scores were similar in both groups.. According to the NICE-

Table 6 Global judgment of efficacy and tolerability

\begin{tabular}{llll}
\hline & HTB & PEP & p \\
\hline Efficacy & & & \\
T1: 2 weeks & $2.6(1.2)$ & $2.4(1.4)$ & 0.76 \\
T2: 8 weeks & $2.1(1.0)$ & $2.3(1.1)$ & 0.53 \\
Tolerability & & & \\
T1: 2 weeks & $2.1(1.0)$ & $1.6(0.7)$ & 0.16 \\
T2: 8 weeks & $1.8(0.8)$ & $1.7(0.7)$ & 0.66 \\
\hline
\end{tabular}


Table 7 Summary of adverse events

\begin{tabular}{|c|c|c|c|c|}
\hline \multirow[b]{2}{*}{ Adverse events } & \multicolumn{2}{|c|}{$\begin{array}{l}\text { HTB Group } \\
(n=21)\end{array}$} & \multicolumn{2}{|c|}{$\begin{array}{l}\text { PEP Group } \\
(n=11)\end{array}$} \\
\hline & $\bar{n}$ & $\%$ & $\bar{n}$ & $\%$ \\
\hline Dizziness during the intervention & 13 & 62 & 1 & 9 \\
\hline Fatigue during the bath & 6 & 29 & & \\
\hline Palpitations during the bath & 4 & 19 & & \\
\hline Itching transient & 4 & 19 & & \\
\hline Heat/sweating transient & 3 & 14 & & \\
\hline Feeling of tightness, transient & 2 & 10 & & \\
\hline Headache, transient & 2 & 10 & & \\
\hline Hunger transient & 1 & 5 & & \\
\hline Insomnia in the night after the bath & 1 & 5 & & \\
\hline Pre-syncope after the bath & 1 & 5 & & \\
\hline Worsening of depressive symptoms in the night after the bath & 1 & 5 & & \\
\hline Irritability transient & 1 & 5 & & \\
\hline Muscle soreness transient & & & 3 & 27 \\
\hline Joint pain transient & & & 3 & 27 \\
\hline Sciatica transient & & & 1 & 9 \\
\hline Tendon pain transient & & & 1 & 9 \\
\hline Cough after sport & & & 1 & 9 \\
\hline
\end{tabular}

guidelines a difference of 3 points in the BDI-II, respectively a decrease of $17.5 \%$ compared to baseline is regarded as clinically relevant [39]. Whether the improvement in sleep in the HTB group after 2 weeks as seen in the PSQI is the cause or the consequence of the improvement in depression cannot be answered with this trial.

The patients' overall global judgment of efficacy showed no difference between the groups. This is similar to the results from Button et al. [52], respectively the TREAD trial [53]. The global rating of change was "better" only with a corresponding mean change of -18.9 in the BDI-II, whereas a mean change of -6.4 was still regarded as "no" improvement.

There were fewer females in the HTB group (59\%) than in the PEP group (87\%); however, in a recent review gender did not modify the antidepressant effect of exercise [34]. In members of the PEP group, symptoms of depression had lingered for a longer period (8 years) than in those of the HBT group (4 years). Because longer duration of depression negatively affects treatment outcome the difference may have influenced the results [54].

Safety concerns existing prior to the study, especially regarding orthostatic dysregulation after HTB in the unsupervised part of the study, were not confirmed. We found some minor transient $\mathrm{AE}$ in both groups, but there were no SAE. Whether HTB is feasible in the home-setting cannot be answered conclusively, because only a few patients bathed there. Although not under investigation, the high attrition rate in the PEP group indicates that physical exercises are not suitable for everyone. Our finding of efficacy of the HTB intervention confirms the results of previous studies [12, 15, 21, 22].

\section{Strengths and limitations}

The strengths of our study are the randomised, controlled design, the use of standardized baths, the good control of body temperature and the use of established patient as well as investigator-related questionnaires.

Several limitations should be discussed. First, the number of dropouts in the PEP group (56.5\%) was far higher than in other trials investigating exercise in depression (18.1\% dropouts). Higher baseline depressive symptoms are predicting a higher number of dropouts and dropout rates are likely to be higher in the outpatient, as in our, than in the inpatient setting [55]. In part, the dropouts in the PEP group are not related to the study (3 patients were hospitalized, 3 developed somatic disorders), but 3 dropped out because of muscle pain and some might have been not motivated. Exercise, therefore may not be suitable for all patients and HTB may for some be better accepted. Second, because of the small sample size, the study has limited power to detect clinically significant differences between the treatment conditions, especially in subgroup analyses. Third, the absence of blinding of treatment conditions, which is inherent and inevitable; 
due to unblinded outcome assessment a risk for performance bias exists. Patient preferences were tried to be kept on a minimum by balancing all information on the study interventions. Fourth, it is a well-known fact that the HAM-D total score has pitfalls; however, for better comparability with other studies, we did not use the GRID-HAM-D, e.g., with better reliability and validity $[56,57]$. Fifth, the validity of paper diary records is limited. Concerns about compliance with paper diaries include poor adherence and retrospective or just-beforea-visit recording [58]. Sixth, there was no structured interview to come to the diagnosis depressive disorder. We relied on the diagnosis by a physician or psychotherapist treating the patients. Seventh, we did not investigate cold application after HTB or the mineral content in the water as potential modifiers of hyperthermia. This might be done in future studies.

\section{Generalizability}

Although external validity may be restricted due to the population selected to participate in clinical studies, the population studied here can be regarded as representative of routine clinical practice, including patients with and without antidepressant medication [59]. Contraindications to HTB are still not well defined. Severe concomitant diseases, i.e. cardiovascular, or orthostatic dysregulation should be omitted, especially in the elderly.

\section{Conclusion}

- HTB added to usual care may be a fast-acting, safe and easy accessible method leading to clinically relevant improvement in depression severity after just 2 weeks but effects may not be further increased with ongoing treatments.

- HTB performed at a thermal bath can be regarded as safe and feasible without external supervision, provided that the patients are informed concerning the potential risks, especially regarding orthostatic dysregulation.

- Patients can apply the method at their own responsibility.

- Exercise may not be feasible in some patients. HTB can also be practiced by patients with problems performing exercise training.

Replication of the results in a large, confirmative trial would clearly have important implications for public health in that the social and financial tolls of moderate to severe depression could be mitigated with a low-cost and easily accessible intervention with high acceptance by patients.

\section{Abbreviations}

BDI-II: Beck Depression Inventar II; Cl: confidence interval; DRKS: German Clinical Trial Register; HAM-D: 17-item Hamilton Depression Rating Scale; HTB: hyperthermic baths; ITT: intention-to-treat; LOCF: last-observationcarried-forward; PEP: Physical Exercise Program; PP: per-protocol; PSQI: The Pittsburgh Sleep Quality Index; SD: standard deviation; WBH: whole body hyperthermia

\section{Acknowledgements}

The authors are grateful to all the participants of the study. We thank Tania Lüty for assistance in preparing the manuscript.

\section{Authors' contributions}

JN: conception and design of the study; manuscript drafting, statistical analysis, critical review of the manuscript. LD: recruitment, screening, enrolment, data acquisition. IK: recruitment, screening, enrolment, data acquisition. GK: manuscript drafting, critical review of the manuscript. $\mathrm{RH}$ : principal investigator, conception and design of the study, manuscript drafting, final revision. The author(s) read and approved the final manuscript.

\section{Funding}

The study was financially supported by the Margarete Müller-Bull Foundation, Gerokstr. 1, 70188 Stuttgart, Germany. The article processing charge was funded by the German Research Foundation (DFG) and the University of Freiburg in the funding program Open Access Publishing. The funders had no role in study design, data collection and analysis, decision to publish, or preparation of the manuscript. Open Access funding enabled and organized by Projekt DEAL.

\section{Availability of data and materials}

The datasets analysed during the current study is available from the corresponding author on reasonable request.

\section{Ethics approval and consent to participate}

The study was approved by the Ethics-Commission of University Freiburg Medical Center (186/16; 2016-07-04) in written form before onset of the study. All participants gave their written informed consent before inclusion in the study.

\section{Consent for publication}

All authors have read and approved the final manuscript and agree with publication of the manuscript in its present form.

\section{Competing interests}

The authors declare that they have no competing interests.

\section{Author details}

'European Institute for Physical Therapy and Balneology, Freiburg, Germany.

${ }^{2}$ University of Freiburg, Faculty of Medicine, Freiburg, Germany.

Received: 23 March 2020 Accepted: 29 October 2020

Published online: 11 November 2020

\section{References}

1. Colton CW, Manderscheid RW. Congruencies in increased mortality rates, years of potential life lost, and causes of death among public mental health clients in eight states. Prev Chronic Dis. 2006;3:A42.

2. Lett HS, Blumenthal JA, Babyak MA, Sherwood A, Strauman T, Robins C, et al. Depression as a risk factor for coronary artery disease: evidence, mechanisms, and treatment. Psychosom Med. 2004;66:305-15.

3. Rudisch B, Nemeroff CB. Epidemiology of comorbid coronary artery disease and depression. Biol Psychiatry. 2003;54:227-40.

4. Sheehan DV, Nakagome K, Asami Y, Pappadopulos EA, Boucher M. Restoring function in major depressive disorder: a systematic review. J Affect Disord. 2017;215:299-313.

5. World Health Organization (WHO). | Depression [http://www.who.int/ mediacentre/factsheets/fs369/en/].

6. Rush AJ, Trivedi MH, Wisniewski SR, Nierenberg AA, Stewart JW, Warden D, et al. Acute and longer-term outcomes in depressed outpatients requiring one or several treatment steps: a STAR*D report. Am J Psychiatry. 2006;163: 1905-17. 
7. Hale MW, Raison CL, Lowry CA. Integrative physiology of depression and antidepressant drug action: implications for serotonergic mechanisms of action and novel therapeutic strategies for treatment of depression. Pharmacol Ther. 2013;137:108-18.

8. Nierenberg AA, Farabaugh AH, Alpert JE, Gordon J, Worthington JJ, Rosenbaum JF, et al. Timing of onset of antidepressant response with fluoxetine treatment. Am J Psychiatry. 2000;157:1423-8.

9. Rantamäki T, Yalcin I. Antidepressant drug action--from rapid changes on network function to network rewiring. Prog Neuro-Psychopharmacol Biol Psychiatry. 2016;64:285-92.

10. Hanusch K, Janssen C. Die passive Ganzkörperhyperthermie in der Psychiatrie - Eine historische analyse; 2013

11. Sarris, J de Manincor, Hargraves, F Tsonis J. Harnessing the Four Elements for Mental Health Front. Psychiatry 2019;10:256 doi: https://doi.org/10.3389/ fpsyt.2019.00256.

12. Gödl R. Veränderungen der autonomen Regulation durch Überwärmungsbadtherapie bei Patienten mit depressiven Störungen. (Changes in autonomic regulation after hyperthermic bath therapy in patients with depressive disorder; unpublished doctoral dissertation, University of Graz, Austria). Medizinischen Fakultät der Karl-FranzensUniversität Graz; 2000.

13. Bunney JN, Potkin SG. Circadian abnormalities, molecular clock genes and chronobiological treatments in depression. Br Med Bull. 2008;86: 23-32.

14. Bauer J, Hohagen F, Gimmel E, Bruns F, Lis S, Krieger S, et al. Induction of cytokine synthesis and fever suppresses REM sleep and improves mood in patients with major depression. Biol Psychiatry. 1995;38:611-21.

15. Naumann J, Grebe J, Kaifel S, Weinert T, Sadaghiani C, Huber R. Effects of hyperthermic baths on depression, sleep and heart rate variability in patients with depressive disorder: a randomized clinical pilot trial. BMC Complement Altern Med. 2017;17(1):172. https://doi.org/10.1186/s12906017-1676-5.

16. Bühring M. Klinik der Hyperthermie: Untersuchungen im Überwärmungsbad. Hippokrates-Verlag; 1984.

17. Harvey AG. Sleep and circadian functioning: critical mechanisms in the mood disorders? Annu Rev Clin Psychol. 2011;7:297-319.

18. Paunio T, Korhonen T, Hublin C, Partinen M, Koskenvuo K, Koskenvuo M, et al. Poor sleep predicts symptoms of depression and disability retirement due to depression. J Affect Disord. 2015;172:381-9.

19. Jawinski P, Kirsten H, Sander C, Spada J, Ulke C, Huang J, et al. Human brain arousal in the resting state: a genome-wide association study. Mol Psychiatry. 2019;24(11):1599-609.

20. Hegerl U, Hensch $T$. The vigilance regulation model of affective disorders and ADHD. Neurosci Biobehav Rev. 2014;44:45-57.

21. Schaper LC. Wiederholte Hyperthermiebehandlung durch Überwärmungsbäder bei Patienten mit depressiven Störungen: Effekte auf die Produktion von Interleukin-6 sowie auf die mittlere Körpertemperatur und den psychopathologischen Befund (Doctoral dissertation, University of Freiburg, Germany). Hochschulverlag; 1996.

22. Janssen CW, Lowry CA, Mehl MR, Allen JJB, Kelly KL, Gartner DE, et al. Whole-body hyperthermia for the treatment of major depressive disorder: a randomized clinical trial. JAMA Psychiatry. 2016;73:789-95.

23. Hanusch $\mathrm{K}-\mathrm{U}$, Janssen $\mathrm{CH}$, Billheimer $\mathrm{D}$, Jenkins I, Spurgeon $\mathrm{E}$, Lowry CA, et al. Whole-body hyperthermia for the treatment of major depression: associations with thermoregulatory cooling. Am J Psychiatry. 2013;170:802-4.

24. Hamilton M. Development of a rating scale for primary depressive illness. $\mathrm{Br}$ J Soc Clin Psychol. 1967:6:278-96.

25. Bunnell DE, Agnew JA, Horvath SM, Jopson L, Wills M. Passive body heating and sleep: influence of proximity to sleep. Sleep. 1988;11:210-9.

26. Horne JA, Reid AJ. Night-time sleep EEG changes following body heating in a warm bath. Electroencephalogr Clin Neurophysiol. 1985;60:154-7.

27. Horne JA, Shackell BS. Slow wave sleep elevations after body heating: proximity to sleep and effects of aspirin. Sleep. 1987;10:383-92.

28. Sung EJ, Tochihara Y. Effects of bathing and hot footbath on sleep in winter. J Physiol Anthropol Appl Hum Sci. 2000;19:21-7.

29. Dorsey CM, Teicher MH, Cohen-Zion M, Stefanovic L, Satlin A, Tartarini W, et al. Core body temperature and sleep of older female insomniacs before and after passive body heating. Sleep. 1999;22:891-8.

30. Dorsey CM, Lukas SE, Teicher MH, Harper D, Winkelman JW, Cunningham $\mathrm{SL}$, et al. Effects of passive body heating on the sleep of older female insomniacs. J Geriatr Psychiatry Neurol. 1996;9:83-90.
31. Mishima Y, Hozumi S, Shimizu T, Hishikawa Y, Mishima K. Passive body heating ameliorates sleep disturbances in patients with vascular dementia without circadian phase-shifting. Am J Geriatr Psychiatry Off J Am Assoc Geriatr Psychiatry. 2005:13:369-76.

32. Orme JG, Reis J, Herz EJ. Factorial and discriminant validity of the Center for Epidemiological Studies Depression (CES-D) scale. J Clin Psychol. 1986;42: 28-33.

33. Josefsson T, Lindwall M, Archer T. Physical exercise intervention in depressive disorders: Meta-analysis and systematic review. Scand J Med Sci Sports. 2014;24:259-72

34. Schuch FB, Dunn AL, Kanitz AC, Delevatti RS, Fleck MP. Moderators of response in exercise treatment for depression: a systematic review. J Affect Disord. 2016;195:40-9.

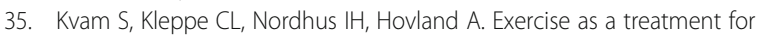
depression: a meta-analysis. J Affect Disord. 2016;202:67-86.

36. Cooney GM, Dwan K, Greig CA, Lawlor DA, Rimer J, Waugh FR, et al. Exercise for depression. Cochrane Database Syst Rev. 2013 [cited 2019 Mar 31]; Available from: https://www.cochranelibrary.com/cdsr/doi/10.1 002/14651858.CD004366.pub6/abstract.

37. Rimer J, Dwan K, Lawlor DA, Greig CA, McMurdo M, Morley W, et al. Exercise for depression. Cochrane Database Syst Rev. 2012;CD004366.

38. Mead GE, Morley W, Campbell P, Greig CA, McMurdo M, Lawlor DA. Exercise for depression. Cochrane Database Syst Rev. 2009;CD004366.

39. National Collaborating Centre for Mental Health. Depression in adults: recognition and management | Guidance and guidelines | NICE [Internet]. [cited 2018 Jan 14]. Available from: https://www.nice.org.uk/guidance/cg90.

40. DGPPN, BÄK, KBV, AWMF (Hrsg.) für die Leitliniengruppe Unipolare Depression*. S3-Leitlinie/Nationale Versor-gungsLeitlinie Unipolare Depression - Langfassung, 2. Auflage. Version 5. 2015.

41. Hallgren M, Stubbs B, Vancampfort D, Lundin A, Jääkallio P, Forsell Y. Treatment guidelines for depression: greater emphasis on physical activity is needed. Eur Psychiatry. 2017:40:1-3.

42. Gutenbrunner C, Hildebrandt G, editors. Handbuch der Balneologie und medizinischen Klimatologie [Internet]. Berlin Heidelberg: Springer-Verlag; 1998 [cited 2018 Apr 19]. Available from: //www.springer.com/de/book/ 9783642800498

43. Chiba T, Yamauchi M, Nishida N, Kaneko T, Yoshizaki K, Yoshioka N. Risk factors of sudden death in the Japanese hot bath in the senior population. Forensic Sci Int. 2005;149:151-8.

44. Zimmerman M, Martinez JH, Young D, Chelminski I, Dalrymple K. Severity classification on the Hamilton depression rating scale. J Affect Disord. 2013; 150:384-8.

45. Beck AT, Steer RA, Brown GK. Beck depression inventory. 2nd ed. San Antonio: The Psychological Corporation; 1996.

46. Kühner C, Bürger C, Keller F, Hautzinger M. Reliability and validity of the Revised Beck Depression Inventory (BDI-II). Results from German samples. Nervenarzt. 2007:78:651-6.

47. Buysse DJ, Reynolds CF III, Monk TH, Berman SR, Kupfer DJ. The Pittsburgh sleep quality index: a new instrument for psychiatric practice and research. Psychiatry Res. 1989;28:193-213.

48. Riemann D, Backhaus J. Behandlung von Schlafstoerungen. Ein psychologisches Gruppenprogramm. Weinheim: Beltz; 1996 [cited 2019 Mar 27]. p. 94-103. Available from: https://scholar.google.com/scholar_ lookup?title=Behandlung\%20von\%20Schlafstoerungen.\%20Ein\%2 Opsychologisches\%20Gruppenprogramm\&publication_year=1996\&author= D\%20Riemann\&author=J\%20Backhaus.

49. Backhaus J, Junghanns K, Broocks A, Riemann D, Hohagen F. Test-retest reliability and validity of the Pittsburgh sleep quality index in primary insomnia. J Psychosom Res. 2002;53:737-40.

50. CIPS, editor. (Ed.). Internationale Skalen für Psychiatrie. Beltz Test: Weinheim; 1977.

51. Hertzog MA. Considerations in determining sample size for pilot studies. Res Nurs Health. 2008;31:180-91.

52. Button KS, Kounali D, Thomas L, Wiles NJ, Peters TJ, Welton NJ, et al. Minimal clinically important difference on the Beck depression inventory - ॥ according to the patient's perspective. Psychol Med. 2015;45:3269-79.

53. Chalder M, Wiles NJ, Campbell J, Hollinghurst SP, Searle A, Haase AM, et al. A pragmatic randomised controlled trial to evaluate the cost-effectiveness of a physical activity intervention as a treatment for depression: the treating depression with physical activity (TREAD) trial. Health Technol Assess Winch Engl. 2012;16:1-164 iii-iv. 
54. Blom MBJ, Spinhoven P, Hoffman T, Jonker K, Hoencamp E, Haffmans PMJ et al. Severity and duration of depression, not personality factors, predict short term outcome in the treatment of major depression. J Affect Disord. 2007:104:119-26

55. Stubbs B, Vancampfort D, Rosenbaum S, Ward PB, Richards J, Soundy A, et al. Dropout from exercise randomized controlled trials among people with depression: a meta-analysis and meta regression. J Affect Disord. 2016; 190:457-66.

56. Williams JBW, Kobak KA, Bech P, Engelhardt N, Evans K, Lipsitz J, et al. The GRID-HAMD: standardization of the Hamilton depression rating scale. Int Clin Psychopharmacol. 2008;23:120-9.

57. Bech P. Rating scales in depression: limitations and pitfalls. Dialogues Clin Neurosci. 2006:8:207-15.

58. Stone AA, Shiffman S, Schwartz JE, Broderick JE, Hufford MR. Patient noncompliance with paper diaries. BMJ. 2002;324:1193-4.

59. McCambridge J, Witton J, Elbourne DR. Systematic review of the Hawthorne effect: new concepts are needed to study research participation effects. J Clin Epidemiol. 2014;67:267-77.

\section{Publisher's Note}

Springer Nature remains neutral with regard to jurisdictional claims in published maps and institutional affiliations.

Ready to submit your research? Choose BMC and benefit from:

- fast, convenient online submission

- thorough peer review by experienced researchers in your field

- rapid publication on acceptance

- support for research data, including large and complex data types

- gold Open Access which fosters wider collaboration and increased citations

- maximum visibility for your research: over $100 \mathrm{M}$ website views per year

At BMC, research is always in progress.

Learn more biomedcentral.com/submissions 